\title{
Hepatic portal venous gas with associated bowel ischaemia and intra-abdominal sepsis after recent chemotherapy
}

\author{
Alexander Marcus Dashwood, ${ }_{1}^{1}$ Robert Mason, ${ }^{2}$ Courtney Jennings, ${ }^{3}$ Priyanka Dhillon ${ }^{1}$
}

'Department of Cardiology, Gold Coast University Hospital, Southport, Queensland, Australia

${ }^{2}$ Department of Oncology, Gold Coast University Hospital, Southport, Queensland, Australia

${ }^{3}$ Gold Coast University Hospital, Southport, Queensland, Australia

\section{Correspondence to} Dr Alexander Marcus Dashwood,

icuris247@googlemail.com

Accepted 21 December 2015

CrossMark

To cite: Dashwood AM, Mason $R$, Jennings $C$, et al. $B M J$ Case Rep Published online: [please include Day Month Year] doi:10.1136/ bcr-2015-213564

\section{DESCRIPTION}

A 31-year-old man with metastatic pancreatic cancer was admitted with acute abdominal pain and distension. He had undergone Whipples surgery 1 year prior for a T3N1b ductal adenocarcinoma of the pancreas and achieved an R1 resection. This was followed by lymph node dissection and splenectomy revealing invasive adenocarcinoma. He was now receiving palliative chemotherapy with modified FOLFOX6, his last cycle being 1 week previously. CT scan 1 month earlier showed progressive hepatic metastasis. Non-contrast CT on presentation identified extensive small bowel ischaemia in the distribution of the superior mesenteric artery. He had substantial intestinal pneumatosis, predominantly small bowel (figure 1), and associated hepatic portal venous gas (HPVG) (figure 2). The peripheral gas distribution seen in HPVG reflects the centrifugal direction of blood flow in the liver. This is differentiated from pneumobilia, which is centrally located due to biliary anatomy and centripetal movement of bile. HPVG is a late sign indicating serious intra-abdominal pathology often requiring urgent surgical intervention. Ischaemic bowel is the primary aetiology in $70 \%$ of HPVG cases, with $91 \%$ relating to transmural necrosis. Mortality rate is $75-90 \%$, which only increases when associated with pneumatosis intestinalis. ${ }^{1}$ The proposed mechanism for gas formation is not well understood but is thought to involve gas-forming organisms crossing the intestinal lumen, into the mesenteric veins, and accumulating in the portal venous system and hepatic parenchyma. ${ }^{2}$ In the case of this patient, with such poor premorbid state and prognosis as well as a standing ARP, the decision was made for palliation.

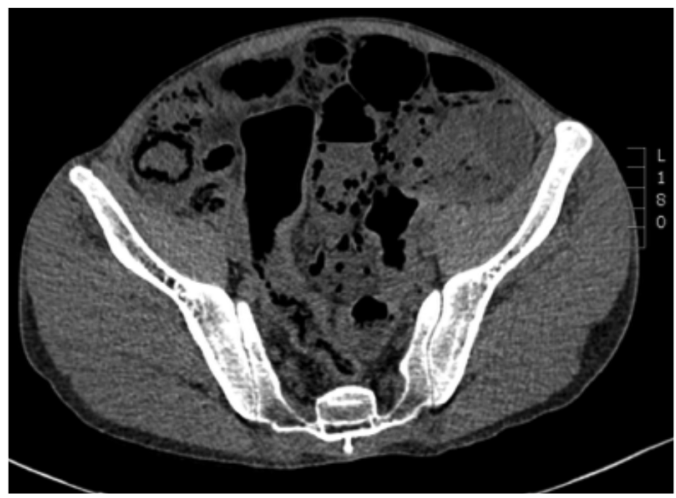

Figure 1 Coronal image revealing hepatic portal venous gas.

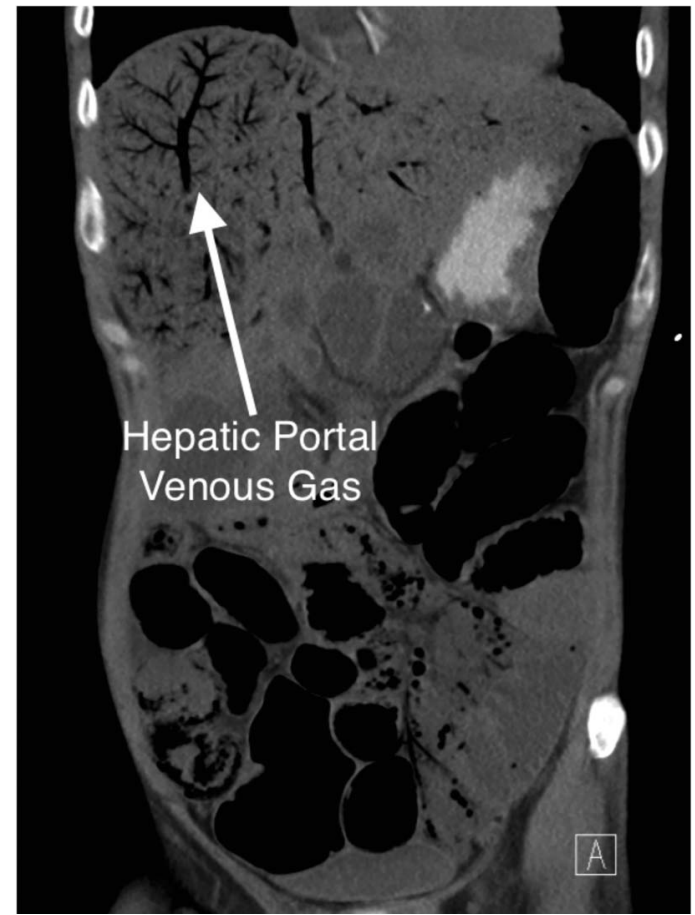

Figure 2 Transverse image revealing hepatic portal venous gas.

\section{Learning points}

- Hepatic portal venous gas is an ominous and late sign indicating severe intra-abdominal pathology, with the most common cause being bowel ischaemia.

- There is high associated mortality.

- Hepatic portal venous gas after chemotherapy is a rare but documented association.

Competing interests None declared.

Patient consent Obtained.

Provenance and peer review Not commissioned; externally peer reviewed.

\section{REFERENCES}

1 Kesarwani V, Ghelani DR, Reece G. Hepatic portal venous gas: a case report and review of literature. Indian J Crit Care Med 2009;13:99-102

2 Abboud B, El Hachem J, Yazbeck T, et al. Hepatic portal venous gas: Physiopathology, etiology, prognosis and treatment. World J Gastroenterol 2009;15:3585-90. 
Copyright 2016 BMJ Publishing Group. All rights reserved. For permission to reuse any of this content visit http://group.bmj.com/group/rights-licensing/permissions.

BMJ Case Report Fellows may re-use this article for personal use and teaching without any further permission.

Become a Fellow of BMJ Case Reports today and you can:

- Submit as many cases as you like

- Enjoy fast sympathetic peer review and rapid publication of accepted articles

- Access all the published articles

- Re-use any of the published material for personal use and teaching without further permission

For information on Institutional Fellowships contact consortiasales@bmjgroup.com

Visit casereports.bmj.com for more articles like this and to become a Fellow 